\title{
Isolation and Characterization of an L-Amino Acid Oxidase-Producing Marine Bacterium
}

\author{
Zhiliang Yu ${ }^{1 *}$, Hua Qiao ${ }^{1}$, Juanping Qiu ${ }^{1}$, Peiya $\mathrm{Xu}^{1}$, Peng $\mathrm{Li}^{2}$ \\ ${ }^{1}$ College of Biological and Environmental Engineering, Zhejiang University of Technology, Hangzhou, China \\ ${ }^{2}$ College of Marine Science and Technology, Zhejiang Ocean University, Zhoushan, China \\ Email: zlyu@zjut.edu.cn
}

Received 2013

\begin{abstract}
One marine bacterial strain, R3, has been newly isolated from the intertidal zone of Dinghai sea area. Measurements of a-keto acids and $\mathrm{H}_{2} \mathrm{O}_{2}$ existing in fermentation supernatant were carried out to show that R3 can produce L-amino acid oxidase (LAAO) with a broad substrate specificity. Physiological and biochemical analysis showed that it can grow great at the conditions with sodium chloride concentration of $1.5 \%-3 \%$, temperature of $15^{\circ} \mathrm{C}-35^{\circ} \mathrm{C}$ and $\mathrm{pH}$ of $6-7$. In addition, molecular identification of 16S rDNA was performed to show that R3 was proximal to Pseudoalteromonas spp. with the highest identity of $98.5 \%$ to Pseudoalteromonas rubra. Therefore, it was designated as Pseudoalteromonas sp. R3. Further studies are required to arrive at a better understanding of this LAAO and secure an application.
\end{abstract}

Keywords: LAAO; Pseudoalteromonas; Physiological Property; Biochemical Property; Identification

\section{Introduction}

L-amino acid oxidase (LAAO; EC 1.4.3.2) is dimeric flavoprotein, and each subunit contains a non-covalently bound FAD molecule as cofactor. It is able to catalyze the stereospecific oxidative deamination of L-amino acids to a-keto acids, $\mathrm{NH}_{4}^{+}$and $\mathrm{H}_{2} \mathrm{O}_{2}$. When $\mathrm{H}_{2} \mathrm{O}_{2}$ is not degraded by catalase, it can cause a decarboxylation of the a-keto acid to the corresponding carboxylic acid.

Diverse studies have indicated that LAAOs have broad bioactivities such as inducing apoptosis [1], cytotoxicity [2,3], edema [4], hemolysis [5], hemorrhage [6], inducing or inhibiting platelet aggregation [7,8], parasite-killing activity [9], and antimicrobial activity [10]. LAAO may act as defence or attack weapons via $\mathrm{H}_{2} \mathrm{O}_{2}$ [11] or as ideal molecular mechanisms for the acquisition of nitrogen from diverse amino acid sources [12]. In addition, researches have showed that LAAO affects the relation of tumor cells with the immune system [13] and is involved in violacein synthesis [14]. So far, LAAO was found to be applied as catalysts in bio-transformation [15] and as part of biosensors in determination of the different forms (D- or L-) of free amino acids [16].

This enzyme has been widely found in nature including snake venoms, insect drugs [17], sea hare, algae [18] and terrestrial microorganisms [19]. In contrast, little is known about LAAO from marine microorganisms. The objective of this study is to isolate and characterize LAAO-

\footnotetext{
"Corresponding author.
}

producing marine microorganism. We believe that this study lays the foundation for further investigation on enzymatic properties, structure, biological function and application of LAAOs from marine microorganisms.

\section{Materials and Methods}

\subsection{Sample Collection and Isolation of LAAO-Producing Marine Microorganism}

The intertidal zone sludge samples $\left(30.03^{\circ} \mathrm{N}, 122.11^{\circ} \mathrm{E}\right)$ were collected from different locations at the Dinghai sea area. From each location, sample was collected at 50 to $100 \mathrm{~cm}$ depth under the sea surface. These samples were placed in special pre-sterilized plastic bottles and brought to the laboratory in aseptic condition. Then, $10 \mathrm{~g}$ of each sludge sample was subjected to $90 \mathrm{~mL}$ of sterilized distilled water and serially diluted (up to 10-6 dilution). After dilution, about $100 \mu \mathrm{L}$ of each diluted sample was plated on different agar medium including PDA (potato $200 \mathrm{~g} / \mathrm{L}$, sucrose $10 \mathrm{~g} / \mathrm{L}$, sea salt $30 \mathrm{~g} / \mathrm{L}$ ), Gause's Medium NO.1 (soluble starch $20 \mathrm{~g} / \mathrm{L}, \mathrm{NaCl} 0.5 \mathrm{~g} / \mathrm{L}$, $\mathrm{K}_{2} \mathrm{HPO}_{4} 0.5 \mathrm{~g} / \mathrm{L}, \mathrm{FeSO}_{4} 0.01 \mathrm{~g} / \mathrm{L}, \mathrm{MgSO}_{4} \cdot 7 \mathrm{H}_{2} \mathrm{O} 0.5 \mathrm{~g} / \mathrm{L}$, $\mathrm{KNO}_{3} 1 \mathrm{~g} / \mathrm{L}$, sea salt $30 \mathrm{~g} / \mathrm{L}$; $\mathrm{pH}$ 7.2-7.4), and MM medium (yeast extract $3 \mathrm{~g} / \mathrm{L}$, peptone $5 \mathrm{~g} / \mathrm{L}$, sea salt $30 \mathrm{~g} / \mathrm{L}$; $\mathrm{pH} 7.2$ - 7.4), and separately incubated at $28^{\circ} \mathrm{C}$ and $25^{\circ} \mathrm{C}$ for 2 - 7 days, as necessary. The isolated colonies were purified by streak-plate technique.

LAAO activity was determined by measuring its fermentation products including $\mathrm{H}_{2} \mathrm{O}_{2}$ and a-keto acids. The 
production of $\mathrm{H}_{2} \mathrm{O}_{2}$ was measured by using Amplex Red Hydrogen Peroxide/Peroxidase Assay kit (Invitrogen, USA). The production of a-keto acids were spectrophotometrically measured based on hydrazine assay, according to Len Sikora's method [20].

\subsection{Sodium Chloride Tolerance and Cultural Condition}

Different concentrations of sodium chloride $(0 \%, 1.5 \%$, $3 \%, 4.5 \%, 6 \%, 7.5 \%, 9 \%, 10.5 \%$ and $12 \%$ ) were added to the MM medium (without sea salt). The seed of isolated LAAO-producer was planted into different MM medium and incubated at $25^{\circ} \mathrm{C}, 160 \mathrm{rpm}$ for 24 hours, and salt tolerance was tested. The growth of the LAAOproducer on $\mathrm{MM}$ medium incubated at different temperature $\left(5^{\circ} \mathrm{C}, 15^{\circ} \mathrm{C}, 25^{\circ} \mathrm{C}, 35^{\circ} \mathrm{C}\right.$ and $\left.45^{\circ} \mathrm{C}\right)$ and at different $\mathrm{pH}(3,4,5,6,7,8,9,10,11$ and 12) was also investigated to determine its growth range of temperature and $\mathrm{pH}$.

\subsection{Physiological and Biochemical Characterization}

The ability of the isolate to utilize various carbon and nitrogen sources, and other physiological and biochemical properties were studied by the method recommended in "The Manual of Systematic Methods of Determinative Bacterial”, with minor modification by adding 3\% sodium chloride to each medium.

\subsection{Sequencing Analysis}

The genomic DNA was isolated by bacterial genomic extraction method (EDTA treatment method). PCR reac-

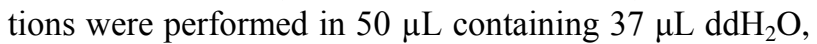
$5 \mu \mathrm{L} 10 \times$ Easy Taq buffer, $4 \mu \mathrm{L} 2.5 \mathrm{mM}$ dNTPs, 100 nM primer 27F (5'-GAGTTTGATCCTGGCTCAG-3'), $100 \mathrm{nM}$ primer 1527R (5'-AGAAAGGAGGTGATCCAGCC-3'), 1 ng genomic DNA, and 1 U Taq DNA polymerase with denaturation at $94^{\circ} \mathrm{C}$ for 5 minutes followed by 30 cycles of 1 minute at $94^{\circ} \mathrm{C}, 50$ seconds at $55^{\circ} \mathrm{C}$, 90 seconds at $72^{\circ} \mathrm{C}$ and a final 10 -minutes extension at $72^{\circ} \mathrm{C}$. At the end of reaction, PCR product was cooled to $4^{\circ} \mathrm{C}$ to await further use. After size confirmation on $1.0 \%$ agarose gel, the PCR DNA product was sent to Sangon Biotech (Shanghai) Co. Ltd for sequencing of $16 \mathrm{~S}$ rDNA. After sequencing, the similarity and homology of partial 16S rDNA were online analyzed using BLAST search via NCBI.

\section{Results}

\subsection{Isolation of LAAO-Producing Strain}

A total of 157 pure isolates were obtained from the intertidal zone of Dinghai sea area located in Zhoushan, Zhe- jiang province, China. Three domains including 32 actinomycetes, 51 fungus and 74 bacteria were morphologically characterized. Out of 157 isolates subjected to screening process, one isolate (R3) showed the capability to produce LAAO based on the below results.

LAAO is able to catalyze the stereospecific oxidative deamination of L-amino acid to a-keto acid. As carbonyl derivative, a-keto acid can be easily measured by sensitive method using 2,4-dinitrophenylhydrazine (DNP) which can react with carbonyl group to generate dinitro-phenylhydrazone with a brown-red color and characteristic absorbance maxima at $520 \mathrm{~nm}$. As shown in Figure 1(c), R3 fermentation supernatant without L-amino acid substrate showed flaxen and $\mathrm{OD}_{520}$ was very low. Similarly, a mixture of R3 fermentation supernatant treated at $95^{\circ} \mathrm{C}$ for 5 minutes and substrate L-Phe (Figure 1(d)) also showed flaxen with low $\mathrm{OD}_{520}$ value. In contrast, medium with L-Phenylpyruvic acid (Figure 1(a)) and R3 fermentation supernatants with L-Phe (Figure 1(b)) both had brown-red color with high $\mathrm{OD}_{520}$. All these results indicate that R3 with L-amino acid substrate can generate a-keto acid. Therefore, R3 can produce LAAO.

LAAO is able to catalyze L-amino acid to release $\mathrm{H}_{2} \mathrm{O}_{2}$ which can be detected using Amplex Red Hydrogen Peroxide/Peroxidase Assay kit. Our results showed that, for either R3 fermentation supernatant without substrate L-Met or R3 fermentation supernatant treated at $95^{\circ} \mathrm{C}$ for 10 minutes followed by addition of L-Met, no $\mathrm{H}_{2} \mathrm{O}_{2}$ was detected. In contrast, huge amount of $\mathrm{H}_{2} \mathrm{O}_{2}$ ( $1.84 \mathrm{mmol} / \mathrm{L})$ was detected in R3 fermentation supernatant with L-Met, indicating that R3 can use L-Met to release $\mathrm{H}_{2} \mathrm{O}_{2}$. Therefore, $\mathrm{R} 3$ can produce LAAO.

\subsection{Morphological Characteristics}

On MM media plate, R3 displayed a red color and round form with smooth. Based on the Gram-staining, R3 was identified as a gram-negative strain with the size of about $3.15 \mu \mathrm{m} \times 1.05 \mu \mathrm{m}(15 \times 100)$.

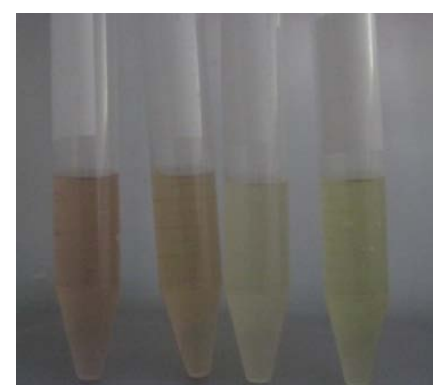

(a) (b) (c) (d)

Figure 1. Detection of a-keto acids. (a) Positive control: Phenylpyruvic acid with $M M$ medium $\left(\mathrm{OD}_{520} 0.202\right)$; (b) L-Phe with R3 (OD $\left.{ }_{520} 0.145\right)$; (c) R3 without L-Phe $\left(\mathrm{OD}_{520} 0.038\right)$; (d) Treatment of $\mathrm{B} 3$ at $95^{\circ} \mathrm{C}$ for 10 minutes followed by adding of $\mathrm{L}-\mathrm{Phe}\left(\mathrm{OD}_{520} \mathbf{0 . 0 5 1}\right)$. 
To determine its substrate specificity, 16 common Lamino acids were selected as substrates for oxidation reaction. It was found that almost 11 out of 16 substrates can be effectively used by $\mathrm{R} 3$ to generate $\mathrm{H}_{2} \mathrm{O}_{2}$ based on Amplex Red Hydrogen Peroxide/Peroxidase Assay kit as shown in Figure 2. L-Leu gave the highest activity, followed by L-Lys, L-Tys, L-Asn, L-Gln, L-Met, L-cystine, L-Arg, L-Trp, $\beta$-Val and L-Glu. On the other hand, the other substrates showed comparatively low activity. These results indicate that $\mathrm{LAAO}$ of R3 has a broad substrate specificity.

\subsection{Sodium Chloride Tolerance and Dependence of Temperature and $\mathrm{pH}$}

To assess $\mathrm{NaCl}$ tolerance of $\mathrm{R} 3$, different concentrations of $\mathrm{NaCl}$ from $0 \%$ to $12 \%$ were added to $\mathrm{MM}$ medium. Figure 3 showed that $\mathrm{R} 3$ needed $\mathrm{NaCl}$ for growth and cannot survive in $\mathrm{NaCl}$-free medium. In addition, it can grow the best with $1.5 \%$ - 3\% of $\mathrm{NaCl}$. Further increase of $\mathrm{NaCl}$ concentration inhibited its growth. All these findings totally agree with the fact that R3 was isolated from the sea area. As expected, both temperature (Figure 4) and $\mathrm{pH}$ (Figure 5) were very important factors for R3 growth. R3 can grow great at temperature between $15^{\circ} \mathrm{C}$ and $35^{\circ} \mathrm{C}$ and the optimal temperature was $25^{\circ} \mathrm{C}$. With the either decrease or increase of temperature, the growth became worse. At either $5^{\circ} \mathrm{C}$ or $45^{\circ} \mathrm{C}$, there was almost no growth. Regarding $\mathrm{pH}, \mathrm{R} 3$ can tolerate basic condition much better than acidic one. The best $\mathrm{pH}$ for $\mathrm{R} 3$ growth was 6 - 7. At $\mathrm{pH}$ lower than 4 , there was almost no growth.

\subsection{Physiological and Biochemical Tests}

In the physiological and biochemical tests (Table 1), R3 showed positive results $(+)$ on starch hydrolysis test, indole test, utilization citrate test and oxidase test, and negative results $(-)$ on lysine decarboxylation enzyme test,

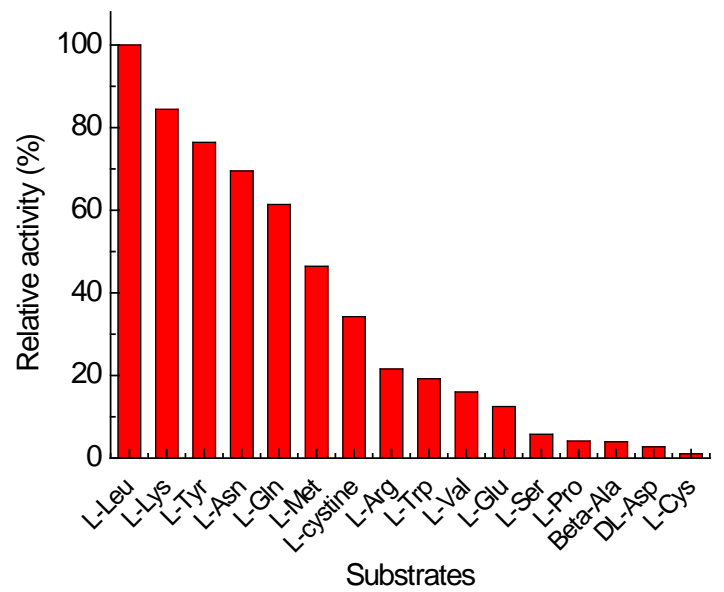

Figure 2. Substrate specificity of R3 LAAO.

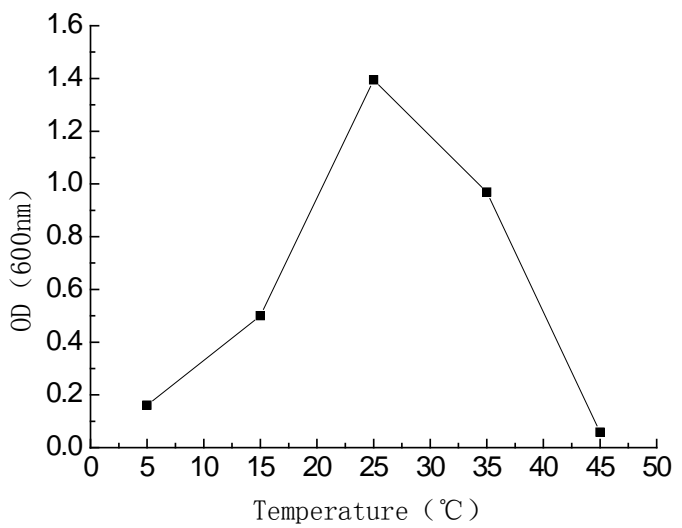

Figure 3. Effect of temperature on the R3 growth.

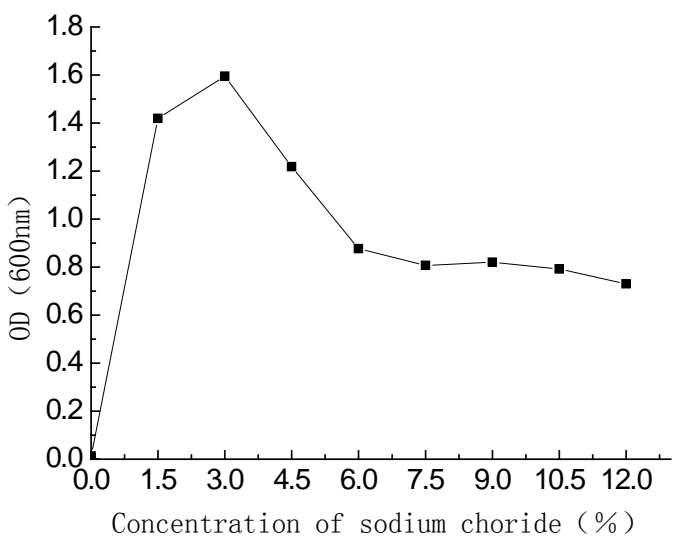

Figure 4. Effect of salt concentration on R3 growth.

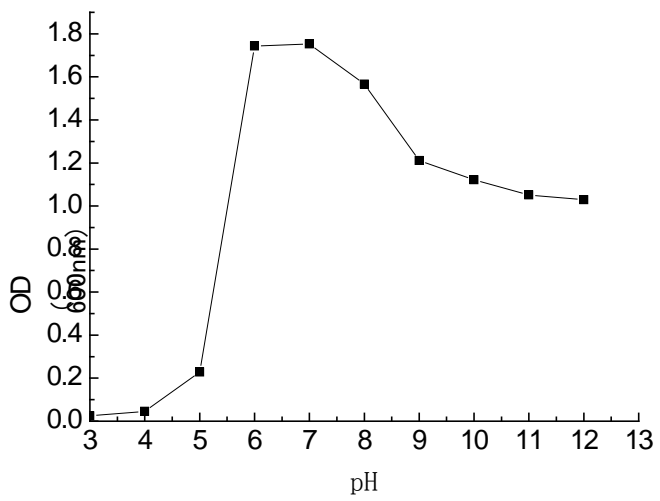

Figure 5. Effect of pH on R3 growth.

half a solid agar test, gelatin hydrolysis test, $\mathrm{H}_{2} \mathrm{~S}$ production test, acetamide test, V-P test, methyl red test and melezitose monohydrate test. It can use carbon sources including galactose, glucose, lactose, fructose, maltose and rhamnose and nitrogen sources including $\left(\mathrm{NH}_{4}\right)_{2} \mathrm{HPO}_{4}$, $\mathrm{KNO}_{3}$, arginine, methionine, glycine and tyrosine.

\subsection{S rDNA Sequence Analysis}

The partial 16S rDNA of R3 was amplified using universal primers 27F and 1527R. After PCR amplification, 
Table 1. Physiological and biochemical characteristics of the R3 isolate.

\begin{tabular}{|c|c|c|c|c|c|}
\hline Items & R3 & Carbon Sources & R3 & Nitrogen Sources & R3 \\
\hline Lysine decarboxylation enzyme & - & Inositol & - & $\left(\mathrm{NH}_{4}\right)_{2} \mathrm{HPO}_{4}$ & + \\
\hline Half a solid agar & - & Sorbitol & - & $\mathrm{KNO}_{3}$ & + \\
\hline Gelatin hydrolysis & - & Mannitol & - & Arginine & + \\
\hline Starch hydrolysis & + & Glucose & + & Methionine & + \\
\hline $\mathrm{H}_{2} \mathrm{~S}$ production & - & Sucrose & - & Phenylalanine & - \\
\hline Indole test & + & Rhamnose & + & Glycine & + \\
\hline Methyl red test & - & Lactose & + & Tyrosine & + \\
\hline V-P test & - & Fructose & + & & \\
\hline Utilization citrate & + & Maltose & + & & \\
\hline Acetamide & - & Galactose & + & & \\
\hline Melezitose monohydrate & - & & & & \\
\hline Oxidase test & + & & & & \\
\hline
\end{tabular}

around 1.4 Kb fragment was successfully obtained (data not shown) and sequenced. Then the Blast search via NCBI was carried out to evaluate the similarity and homology of R3 with other organisms. It was found that R3 had very high homology with Pseudoalteromonas spp., with the highest identity of $98.5 \%$ to Pseudoalteromonas rubra. Therefore, we designated it as Pseudoalteromonas sp. R3.

\section{Discussion}

LAAOs form a family of proteins with various enzymatic properties, structure and biological function. Extensive studies indicate that LAAOs have promising biotechnological and medical applications. This enzyme is widely distributed in nature including snake venoms, insect drugs, sea hare, fungi, bacteria and algae. Unlike snake venom LAAOs which have been widely and deeply investigated to show broad bioactivities such as apoptosis, cytotoxicity, edema, hemolysis, hemorrhage, platelet aggregation, parasite-killing activity and antimicrobial activity, nonsnake venom LAAOs need to be further studied and their functional role and application remain to be revealed. Especially, very little is known about LAAOs from marine microorganism. In this study, we successfully isolated an LAAO-producing marine bacterium from intertidal zone of Dinghai sea area. Based on physiological and biochemical tests together with molecular analysis, it was designated as Pseudoalteromonas sp. R3. To arrive at a better understanding and address the commercialization of LAAO from this isolate, future works are planned to clone the gene coding for this Pseudoalteromonas sp. R3 LAAO and to study its structure, biological and physiological roles, relationship between function and structure, and mechanism of transcription in vivo.

\section{Acknowledgements}

This work was supported by Natural Science Foundation of Zhejiang Province, China (Y5100153), Welfare Tech- nology Applied Research Project of Zhejiang Province, China (2011C23007), and Natural Science Foundation of ZJUT (20100213) to Z.L. Yu.

\section{REFERENCES}

[1] S. Torii, M. Naito and T. Tsuruo, “Apoxin I, a Novel Apoptosis-Inducing Factor with L-Amino Acid Oxidase Activity Purified from Western Diamondback Rattlesnake Venom,” Journal of Biological Chemistry, Vol. 272, No. 14, 1997, pp. 9539-9542.

http://dx.doi.org/10.1074/jbc.272.14.9539

[2] G. B. Naumanna, L. F. Silvaa, L. Silvaa, G. Faria, M. Richardson, K. Evangelista, et al., "Cytotoxicity and Inhibition of Platelet Aggregation Caused by an L-Amino Acid Oxidase from Bothrops leucurus Venom," Biochimica et Biophysica Acta, Vol. 1810, No. 7, 2011, pp. 683-694. http://dx.doi.org/10.1016/j.bbagen.2011.04.003

[3] M. Y. Ahn, B. M. Lee and Y. S. Kim, "Characterization and Cytotoxicity of L-Amino Acid Oxidase from the Venom of King Cobra (Ophiophagus hannah)," The International Journal of Biochemistry \& Cell Biology, Vol. 29, No. 6, 1997, pp. 911-919.

http://dx.doi.org/10.1016/S1357-2725(97)00024-1

[4] R. G. Stábeli, S. Marcussi, G. B. Carlos, R. C. Pietro, H. S. Selistre-de-Araújo, J. R. Giglio, et al., "Platelet Aggregation and Antibacterial Effects of an L-Amino Acid Oxidase Purifie d from Bothrops alternatus Snake Venom,” Bioorganic \& Medicinal Chemistry, Vol. 12, No. 11, 2004, pp. 2881-2886. http://dx.doi.org/10.1016/j.bmc.2004.03.049

[5] Y. Abe, Y. Shimoyama, H. Munakata, J. Ito, N. Nagata and K. Ohtsuki, "Characterization of an Apoptosis-Inducing Factor in Habu Snake Venom as a Glycyrrhizin (GL)Binding Protein Potently Inhibited by GL in Vitro," Biological \& Pharmaceutical Bulletin, Vol. 21, No. 9, 1998, pp. 924-927. http://dx.doi.org/10.1248/bpb.21.924

[6] D. H. Souza, L. M. Eugenio, J. E. Fletcher, M. S. Jiang, R. C. Garratt, G. Oliva, et al., "Isolation and Structural Characterization of a Cytotoxic L-Amino Acid Oxidase from Agkistrodon contortrix laticinctus Snake Venom: Preliminary Crystallographic Data," Archives of Biochemistry 
and Biophysics, Vol. 368, No. 2, 1999, pp. 285-290. http://dx.doi.org/10.1006/abbi.1999.1287

[7] H. Takatsuka, Y. Sakurai, A. Yoshioka, T. Kokubo, Y. Usami, M. Suzuki, et al., "Molecular Characterization of L-Amino Acid Oxidase from Agkistrodon halys blomhoffii with Special Reference to Platelet Aggregation," Biochimica et Biophysica Acta-Protein Structure and Molecular Enzymology, Vol. 1544, No. 1-2, 2001, pp. 267-277. http://dx.doi.org/10.1016/S0167-4838(00)00229-6

[8] S. A. Alib, S. Stoevab, A. Abbasi, J. M. Alam, R. Kayed, M. Faigle, et al. "Isolation, Structural, and Functional Characterization of an Apoptosis-Inducing L-Amino Acid Oxidase from Leaf-Nosed Viper (Eristocophis macmahoni) Snake Venom," Archives of Biochemistry and Biophysics, Vol. 384, No. 2, 2000, pp. 216-226. http://dx.doi.org/10.1006/abbi.2000.2130

[9] P. Deolindo, A. S. Teixeira-Ferreira, R. A. DaMatta and E. W. Alves, "L-Amino Acid Oxidase Activity Present in Fractions of Bothrops jararaca Venom Is Responsible for the Induction of Programmed Cell Death in Trypanosoma cruzi,” Toxicon, Vol. 56, No. 6, 2010, pp. 944-955. http://dx.doi.org/10.1016/j.toxicon.2010.06.019

[10] B. G. Stilesa, F. W. Sextona and S. A. Weinstein, “Antibacterial Effects of Different Snake Venoms: Purification and Characterization of Antibacterial Proteins from Pseudechis australis (Australian King Brown or Mulga Snake) Venom,” Toxicon, Vol. 29, No. 9, 1991, pp. 1129-1141. http://dx.doi.org/10.1016/0041-0101(91)90210-I

[11] Y. Hsiuchin, M. J. Paul, K. Ko-Chun, M. Kamio, M. W. Germann, C. D. Derby and P. C. Tai, "Cloning, Characterization and Expression of Escapin, a Broadly Antimicrobial FAD-Containing L-Amino Acid Oxidase from Ink of the Sea Hare Aplysia californica," The Journal of Experimental Biology, Vol. 208, No. pt 18, 2005, pp. 3609-3622. http://dx.doi.org/10.1242/jeb.01795

[12] M. A. Davis, M. C. Askin and M. J. Hynes, “Amino Acid Catabolism by an Area-Regulated Gene Encoding an LAmino Acid Oxidase with Broad Substrate Specificity in Aspergillus nidulans," Applied and Environmental Microbiology, Vol. 71, No. 7, 2005, pp. 3551-3555. http://dx.doi.org/10.1128/AEM.71.7.3551-3555.2005

[13] A. Carbonnelle-Puscian, C. Copie-Bergman, M. Baia, N. Martin-Garcia, Y. Allory, C. Haioun, et al. "The Novel Immunosuppressive Enzyme IL4I1 Is Expressed by Neo- plastic Cells of Several B-Cell Lymphomas and by Tumor-Associated Macrophages,” Leukemia, Vol. 23, No. 5, 2009, pp. 952-960. http://dx.doi.org/10.1038/leu.2008.380

[14] R. Genet, P. H. Benetti, A. Hammadi and A. Menez, "LTryptophan 2',3'-Oxidase from Chromobacterium violaceum. Substrate Specificity and Mechanistic Implications,” The Journal of Biological Chemistry, Vol. 270, No. 40, 1995, pp. 23540-23545. http://dx.doi.org/10.1074/jbc.270.40.23540

[15] R. L. Hanson, K. S. Bembenek, R. N. Patel and L. J. Szarka, "Transformation of N-Epsilon-CBZ-L-Lysine to CBTL-Oxylysine Using L-Amino Acid Oxidase from Providencia Alcalifaciens and L-2-Hydroxy-Iso-Caproate Dehydrogenase from Lactobacillus confuses," Applied Microbiology and Biotechnology, Vol. 37, No. 5, 1992, pp. 599-603. http://dx.doi.org/10.1007/BF00240733

[16] M. Varadi, N. Adanyi, E. E. Szabo and N. Trummer, "Determination of the Ratio of D-and L-Amino Acids in Brewing by an Immobilize Amino Acid Oxidase Enzyme Reactor Coupled to Amperometric Detection,” Biosensors \& Bioelectronics, Vol. 14, No. 3, 1999, pp. 335-340. http://dx.doi.org/10.1016/S0956-5663(98)00130-4

[17] M. Y. Ahn, K. S. Ryu, Y. W. Lee and Y. S. Kim, "Cytotoxicity and L-Amino Acid Oxidase Activity of Crude Insect Drugs,” Archives of Pharmacal Research, Vol. 23, No. 5, 2000, pp. 477-481. http://dx.doi.org/10.1007/BF02976576

[18] K. Ito, K. Hori and K. Miyazawa, "Purification and Some Properties of L-Amino Acid Oxidase from Amphiroa crassissima Yendo," Hydrobiologia, Vol. 152, 1987, pp. 563-569. http://dx.doi.org/10.1007/BF00046183

[19] G. M. Brearley, C. P. Price, T. Atkinson and P. M. Hammond, "Purification and Partial Characterisation of a BroadRange L-Amino Acid Oxidase from Bacillus carotarum 2Pfa Isolated from Soil," Applied Microbiology and Biotechnology, Vol. 41, No. 6, 1994, pp. 670-676. http://dx.doi.org/10.1007/BF00167283

[20] L. Sikora and G. A. Marzluf, "Regulation of L-Amino Acid Oxidase and of D-Amino Acid Oxidase in Neurospora crassa," Molecular \& General Genetics, Vol. 186, No. 1, 1982, pp. 33-39. http://dx.doi.org/10.1007/BF00422908 